\title{
Region based Diversity Studies of Saccharomyces cerevisiae and Lentinula edodes
}

\author{
Keshani $^{1}$, Shivani Sharma ${ }^{1 *}$, S.S. Kanwar ${ }^{2}$, P.K. Khanna ${ }^{1}$ and Shammi Kapoor ${ }^{1}$ \\ ${ }^{1}$ Department of Microbiology, College of Basic Sciences and Humanities, Punjab Agricultural \\ University, Ludhiana 141004, Punjab, India \\ ${ }^{2}$ Department of Microbiology, College of Basic Sciences, Himachal Pradesh Agricultural \\ University, Palampur 176062, HP, India
}

*Corresponding author

\section{A B S T R A C T}

\section{Keywords}

Saccharomyces cerevisiae,

Lentinula edodes, Diversity, PCRRFLP and SDSPAGE

Article Info

Accepted:

26 June 2018

Available Online:

10 July 2018

\begin{abstract}
Microbial diversity is the main key point during the studies of microbial ecology. The diversity of edible fungal species in an area affects the nutritional behavior of that community. Hence, the present study has been designed for assessing the diversity of two very important fungal genera involved in eating habits of the Indians i.e. Saccharomyces cerevisiae and Lentinus edodes using different molecular as well as protein markers. The results revealed the divergent nature of these two genera on the basis of their geographical origins. PCR-RFLP analysis of $S$. cerevisiae strains from Northern India clustered them into two groups one with four strains from different locations and other with fourteen strains, most of which from the same geographical location i.e. Lahaul and Spiti. Two indigenous strains of $L$. edodes from Tamil Nadu Agricultural University, Coimbatore (LeC and LeI) showed different characteristics as compared to other strains as seen by protein profiling using SDS-PAGE and isozymes. This study gives an indication of these techniques to be a powerful tool to discriminate these fungal species at intraspecies level for their diversity analysis.
\end{abstract}

\section{Introduction}

India is a rich repository of microbial genetic diversity. There are number of fungal species that are associated with the eating habits and health benefits of the Indians. The most famous yeast comes under ascomycetes family of fungi, Saccharomyces cerevisiae, which is associated with most of the fermented foods of the Indian origin (Walia et al., 2014). The fermented foods are more common among people belonging to the rural areas, especially in hilly and tribal people. The quality of a fermented product is consequence of the starter and progressive presence of microbial flora during the process of fermentation. To obtain the best strain, the knowledge of natural yeast diversity available in the given area or yeast(s) associated with a particular product, is of prime importance (Kanwar and Keshani 2014). Eighteen S. cerevisiae strains isolated from various fermented foods of Western 
Himalayas had already been available with the Department of Microbiology, Himachal Pradesh Agricultural University, Palampur were used in the present study. These strains were discriminated at genetic level using internal transcribed spacer (ITS) region and were found to possess potential fermentation traits both in baking as well as brewing aspects (Keshani et al., 2015). However, to study their diversity on the basis of different geographical locations and to discriminate them at intraspecies level other molecular technique is needed to be used.

The other most important fungal species is Lentinula edodes, of basidiomycetes family, commonly known as Xianggu or shiitake is one of the white-rot fungi growing on the dead tree or sawdust and ranks second in the global mushroom market after Agaricus bisporus (Bisen et al., 2010). This mushroom grows throughout East and Southeast Asia and possesses abundant amount of proteins, bioactive polysaccharides such as $\beta$-D-glucan, heteroglucan, xylomannan, lentinan and eritadenine; free sugars including arabinose, arabitol, mannose, mannitol, trehalose and glycerol; vitamins (B2, B12, D2) and dietary fibre (Hobbs 2000). These nutritional components render shiitake overwhelmingly popular with consumers in Asian countries. The presence of different bioactive components in $L$. edodes aids in its pharmacological and therapeutical potential against hypertension, hyperlipidemia and cardiovascular complications, depressed immunity, hepatic disorders and cancer. Mostly, morphological parameters such as the size, shape, form, gills, basidium, and basidiospores are used for basidiomycetes identification, but differentiations of closely related cultures at molecular level require extensive molecular techniques. These molecular approaches are considered as one of the efficient biotechnological tool for assessment of genetic diversity (Mehmood et al., 2008) and have been proven to be effective in the classification of fungal taxonomic groups including mushrooms (Le $e t$ al., 2008).

Therefore, the present study have been planned with the objective of exploring intraspecies variability among eighteen $S$. cerevisiae strains at molecular level using PCR-RFLP technique and seven Lentinula edodes strains at protein level using sodium dodecylsulfate polyacrylamide gel electrophoresis (SDS-PAGE) and isozyme analysis.

\section{Materials and Methods}

\section{S. cerevisiae strains}

Eighteen strains of S. cerevisiae used for PCRRFLPhad been available with the Department of Microbiology, Himachal Pradesh Agricultural University, Palampur. These strains were isolated from various fermented foods of Western Himalayas from different tribal geographical locations.

\section{L. edodes strains}

Seven strains of L. edodes used for SDSPAGE and isozyme analysis included five strains, namely, LeS, OE-38, OE-142, OE329 , and OE-388 procured from the germplasm collection of edible mushrooms, Directorate of Mushroom Research, Solan, India and two indigenous strains $(\mathrm{LeC}$ and LeI) obtained from Tamil Nadu Agricultural University, Coimbatore, India.

\section{PCR-RFLP of ITS region of Saccharomyces cerevisiae strains}

DNA extraction, amplification and visualization

Thermo Scientific Phire Plant Direct PCR Kit, 
F-130 was used to perform polymerase chain reaction (PCR) directly from the yeast cells. Based on optimization trials, the standardized PCR protocol for $50 \mu 1$ reaction mixture; included, $25 \mu \mathrm{l}$ of $2 \mathrm{X}$ phire plant PCR buffer, $0.6 \mu \mathrm{l}$ of $10 \mu \mathrm{M}$ of primer set containing forward and reverse primers, $1 \mu \mathrm{l}$ of phire hot start II DNA polymerase, $0.5 \mu$ l of yeast cells grown in potato dextrose broth (PDB) and sterilized milli-Q water to make up the reaction volume. The PCR products were resolved in $2.0 \%$ agarose gel in $1 \mathrm{x}$ tris acetate EDTA buffer containing ethidium bromide $(0.5 \mu \mathrm{g} / \mathrm{mL})$ at $75 \mathrm{~V}$ for 90 minutes.

\section{Digestion of PCR products}

The PCR products were digested without further purification with four restriction endonucleases i.e. AluI, HaelII, HinfI and TaqI by the following protocol:

$\begin{array}{ll}\text { PCR product: } & 10 \mu \mathrm{l} \\ \text { Buffer: } & 2 \mu \mathrm{l} \\ \text { Restriction enzyme: } & 0.5 \mu \mathrm{l} \\ \text { Distilled water: } & 7.5 \mu \mathrm{l}\end{array}$

The mixture was incubated at $37{ }^{\circ} \mathrm{C}$ for two hours except for TaqI, where incubation temperature was $60{ }^{\circ} \mathrm{C}$, the restriction fragments were separated on $1.2 \%$ agarose gel in 1X TAE buffer. The gels were stained with ethidium bromide, visualized under UV light and photographed by UVITEC, Cambridge, GeNei ${ }^{\mathrm{TM}}$. Sizes of different bands were estimated by comparison with a DNA length standard. The PCR-RFLP analyses were carried out using Treeconw software program.

\section{SDS-PAGE and isozyme analysis of Lentinula edodes strains}

Pure mycelial cultures of the seven L. edodes strains were aseptically inoculated in $100 \mathrm{~mL}$ potato dextrose broth (PDB) medium and incubated at $25 \pm 2^{\circ} \mathrm{C}$ for 4 weeks. The mycelial mat was harvested by filtering the broth through Whatman no. 1 filter paper and harvested mycelium was used for SDS-PAGE and isozyme extraction.

\section{Extract preparation}

About $10 \mathrm{~g}$ of fresh mycelium of each strain was taken in $50 \mathrm{~mL}$ of $0.5 \mathrm{M}$ Tris- $\mathrm{HCl}$ buffer $(\mathrm{pH}$ 6.8), homogenised in a tissue homogeniser and transferred to the centrifugation tubes. The homogenized mycelium were then centrifuged $(10,000 \mathrm{rpm}$, $10 \mathrm{~min})$. The supernatant was then saturated to $80 \%$ by ammonium sulphate, centrifuged $(10,000 \mathrm{rpm}, 20 \mathrm{~min})$. Supernatant was discarded and the residue was dissolved in a minimum amount of $0.5 \mathrm{M}$ Tris- $\mathrm{HCl}$ buffer ( $\mathrm{pH}$ 6.8), dialysed to remove the impurities. After dialysis the solutions were again centrifuged at $4^{\circ} \mathrm{C}$ at $6000 \mathrm{rpm}$ for $5 \mathrm{~min}$, the supernatant was discarded and the residue was dissolved in minimum amount of buffer.

\section{Protein estimation}

The protein content of the samples was estimated by Lowry's method (Lowry et al.1951) with bovine serum albumin (BSA) as the internal standard.

\section{Gel electrophoresis}

SDS-PAGE was carried out according to the modified method of Laemmli (1970) under reducing conditions (2-mercaptoethanol) with $12 \%$ resolving gel and 5\% stacking gel. Protein bands were visualized by staining the gel with $45 \%$ (V/V) methanol, 10\% (V/V) acetic acid for $30 \mathrm{~min}$ and stained with 0.25 $(\mathrm{m} / \mathrm{V})$ Coomassie Brilliant Blue R-250 in fixing solution and later destained by incubating the gel in $40 \%(\mathrm{~V} / \mathrm{V})$ methanol, $7.5 \%(\mathrm{~V} / \mathrm{V})$ acetic acid. The molecular masses of protein bands were calculated using the broad range SDS-PAGE molecular mass standards. 
Isozyme analysis was carried out for three different enzymes namely alcohol dehydrogenase, malate dehydrogenase and peroxidase as native PAGE using $2.5 \%$ stacking gel and $12 \%$ resolving gel. After electrophoresis, gel was stained using specific staining systems in the presence of the specific substrates for different enzymes. Different staining systems were used for different isozymes viz., alcohol dehydrogenases (Tanksley 1979), malate dehydrogenases (Brown et al., 1978) and peroxidases (Guikema and Sherman 1980)

After destaining, the protein bands appeared in the gel was visualized for the polymorphism among the different strains. The relative mobility $\left(\mathrm{R}_{\mathrm{m}}\right)$ was calculated by measuring the distance moved by the dye and different protein bands as follows:

$\mathrm{Rm}=$

Distance travelled by the protein band $(\mathrm{cm})$

Distance travelled by the tracking dye $(\mathrm{cm})$

\section{Results and Discussion}

\section{PCR-RFLP of ITS region of $S$. cerevisiae strains}

The ITS regions of the indigenous yeast isolates were amplified using primers ITS1 and ITS4. The ITS region of all the strains amplified about 880 bp sequences. The PCR products were digested with four restriction endonucleases: Alu I, Hae III, Hinf I and Taq $I$. The RFLP analysis grouped these strains in two groups; one with $90 \%$ similarity and the other with 85\% similarity (Fig. 1). All eighteen $S$. cerevisiae strains shared almost same restriction patterns with endonucleases Alu I, Hae III, Hinf I and Taq I (Table 1), suggesting a relationship among them in the restriction pattern of internal transcribed spacer region, however, with a divergent nature as the grouping of strains was not location based (Fig. 2). The second cluster consisted of strains from Sangla, Lahaul \& Spiti and Bharmour region whereas, all the other strains were grouped in first cluster.

S. cerevisiae has been studied extensively due to its importance in the production of various fermented foods and beverages (Kanwar and Keshani, 2016). However, this species is also able to cause spoilage (Martorell et al., 2005); therefore, food industry is interested in defining methods that can discriminate between isolates of $S$. cerevisiae. A typing technique, in which restriction fragment length polymorphism in the rDNA repeat of various isolates of Candida albicans was generated, showed that this technique enabled the discrimination at intraspecies level (Magee $e t$ al., 1987). Chromosomal length polymorphism has also been shown in baker's (Casey et al., 1990) and brewer's yeast (Pedersen 1986) strains. Walther et al., (2014) also stated that by using PCR-RFLP two types of lager yeasts could be distinguished, showing it to be a powerful technique for discrimination at intra-species level. Thus, the use of restriction enzymes to generate restriction patterns from the amplified rDNA regions seems to be a beneficial approach to discriminate $S$. cerevisiae at intra-species level. Molina et al., (1993) have amplified part of the $3^{\prime}$ external transcribed spacer and the intergenic spacer, which after digestion with Mspl allowed discrimination of strains between and within the species $S$. cerevisiae, $S$. pastorianus and $S$. carlsbergensis. It has been shown that the ITS regions have a significant level of length and sequence polymorphism across fungal species (Feibelman et al., 1994).

\section{SDS-PAGE and isozyme analysis of $L$.} edodes

The protein profile of all the seven strains was evaluated for relatedness amongst the strains. 
The samples used for molecular characterization by SDS-PAGE were estimated for the protein content before being used in generating the protein profiles (Table 2). The maximum protein content was obtained in OE-388 $\left(176.6 \mu \mathrm{g} \mathrm{ml}^{-1}\right)$ followed by LeS $\left(152.9 \mu \mathrm{g} \mathrm{ml}^{-1}\right)$ and OE-38 $(151.2 \mu \mathrm{g}$ $\mathrm{ml}^{-1}$ ).

Slight variation was observed in the banding pattern among the strains (Table 3). Five strains (LeS, OE-38, OE-142, OE-329 and OE-388) showed one band having similar relative mobility value of 0.78 . Maximum number of bands ( 8 bands) were observed in OE-329 while minimum (5 bands) were in LeI and OE-142. Three bands having similar relative mobility were obtained in three strains (OE-38, OE-142 and OE-388). The protein profiles were obtained for all the strains. The banding pattern obtained after electrophoresis was used to evaluate the similarities and dissimilarities among the strains (Plate 1).

Results of SDS-PAGE indicated similarity among LeS, OE-38, OE-142, OE-329 and OE388 . The one band formed at relative mobility of 0.78 had molecular weight of $18.7 \mathrm{kDa}$, respectively. However, the maximum similarity was observed in three stains of $L$. edodes (OE-38, OE-142 and OE-388). The three bands formed at relative mobility of $0.02,0.36$ and 0.78 had molecular weight of > $97 \mathrm{kDa}, 44 \mathrm{kDa}$ and $18.7 \mathrm{kDa}$, respectively.

Almost similar molecular weight proteins have been reported in Lentinus spp. by several workers. Kobayashi et al., (2003) isolated two new RNase T2 Ribonucleases, RNase Le37 and Irp3 with a molecular mass of $45 \mathrm{kDa}$ from basidiomycetous fungi, $L$. edodes and Irpexlacteus. Vetchinkina et al., (2008) isolated a number of lectins varying in polypeptide composition and carbohydrate specificity from $L$. edodes at different stages of its morphogenesis: non pigmented mycelium, brown mycelium film and fruiting body. SDS-PAGE identified three lectins at the non pigmented mycelium stage, two of them being dimers consisting of 16 and 45 $\mathrm{kDa}$ and 16 and $42 \mathrm{kDa}$ subunits; the third was a tetramer of $16,39,42$ and $45 \mathrm{kDa}$ subunits. The fractions with lectin activity obtained at the brown mycelium film stage contained polypeptides of 24,30 and $38 \mathrm{kDa}$. Thetsrimuang et al., (2011) reported that the crude polysaccharides from the fresh and the dried fruiting bodies of Lentinus sp. (RJ-2) had protein bands which had molecular weights lower than $20.1 \mathrm{kDa}$ and around 66.0$97.0 \mathrm{kDa}$.

\section{Isozyme analysis of $L$. edodes strains}

Isozyme analysis was carried out for three different enzymes namely alcohol dehydrogenase, malate dehydrogenase and peroxidase as native PAGE.

\section{Alcohol dehydrogenase}

Two bands corresponding to two isozymes were obtained for alcohol dehydrogenase (Plate 2 a). The relative mobility $(\mathrm{Rm})$ values of the two bands were 0.13 and 0.24 . A single band at $\mathrm{Rm}$ value of 0.13 was observed in four strains (LeS, OE-38, OE-142 and OE-329). An additional band at $\mathrm{Rm}$ value of 0.24 was observed in OE-142 along with another band at $\mathrm{Rm}$ value of 0.13 (Table 4). However, the additional band of $\mathrm{Rm}$ value (0.24) was also observed in OE-388 strain. Chakraborty and Sidkar (2008) obtained two ADH isozymes in protoplasts between $P$. florida and $V$. volvacea. Chakraborty and Sidkar (2010) again obtained two isozymes for fusion products of $P$. florida and Calocybeindica 
Table.1 Restriction analysis of the ITS1-5.8S-ITS2 region from eighteen S. cerevisiae strains

\begin{tabular}{|c|c|c|c|c|c|}
\hline & Place of & \multicolumn{4}{|c|}{ Restriction Fragments (size) } \\
\cline { 3 - 6 } Strains & Collection & Alu I & Hae III & Hinf I & Taq I \\
\hline Sc01 & Lahaul\&Spiti & $660+50$ & $310+250+120+50$ & $360+300+70$ & $280+250+140+60$ \\
\hline Sc02 & Lahaul\&Spiti & $660+50$ & $310+250+110+60$ & $360+300+70$ & $280+250+130+70$ \\
\hline Sc03 & Lahaul\&Spiti & $660+50$ & $310+250+120+50$ & $360+300+70$ & $280+250+140+60$ \\
\hline Sc04 & Lahaul\&Spiti & $660+50$ & $310+250+100+70$ & $360+300+70$ & $280+250+140+60$ \\
\hline Sc05 & Lahaul\&Spiti & $660+50$ & $310+250+100+70$ & $360+320+50$ & $250+230+150+80$ \\
\hline Sc06 & Lahaul\&Spiti & $660+50$ & $310+250+120+50$ & $360+300+70$ & $280+250+140+60$ \\
\hline Sc07 & Lahaul\&Spiti & $660+50$ & $310+250+120+50$ & $360+300+70$ & $280+250+140+60$ \\
\hline Sc08 & Lahaul\&Spiti & $660+50$ & $310+250+120+50$ & $360+300+70$ & $280+250+140+60$ \\
\hline Sc09 & Lahaul\&Spiti & $660+50$ & $310+250+120+50$ & $360+300+70$ & $280+250+140+60$ \\
\hline Sc10 & Sangla & $660+50$ & $310+250+120+50$ & $360+300+70$ & $280+250+140+60$ \\
\hline Sc11 & Sangla & $660+50$ & $310+250+120+50$ & $360+320+50$ & $300+250+130+50$ \\
\hline Sc12 & Sangla & $660+50$ & $310+250+120+50$ & $360+320+50$ & $300+250+130+50$ \\
\hline Sc15 & Bharmour & $660+50$ & $310+250+100+70$ & $360+320+50$ & $280+250+140+60$ \\
\hline Sc16 & Pangi & $660+50$ & $310+250+120+50$ & $360+300+70$ & $280+250+140+60$ \\
\hline Sc19 & Sangla & $660+50$ & $310+250+120+50$ & $360+300+70$ & $300+250+130+50$ \\
\hline Sc20 & Sangla & $660+50$ & $310+250+120+50$ & $360+320+50$ & $280+250+140+60$ \\
\hline Sc21 & Sangla & $660+50$ & $310+250+120+50$ & $360+320+50$ & $280+250+140+60$ \\
\hline Sc22 & Palampur & $660+50$ & $310+250+120+50$ & $360+300+70$ & $280+250+140+60$ \\
\hline
\end{tabular}

Table.2 Estimation of protein content in L. edodes strains

\begin{tabular}{|c|c|}
\hline Strains & Protein content $\left(\mu \mathrm{g} \mathrm{ml}^{-1}\right)$ \\
\hline LeC & 45.53 \\
\hline LeI & $\mathbf{6 8 . 3 0}$ \\
\hline LeS & 152.9 \\
\hline OE-38 & 151.2 \\
\hline OE-142 & $\mathbf{9 6 . 3 0}$ \\
\hline OE-329 & 115.69 \\
\hline OE-388 & 176.6 \\
\hline CD at 5\% & 1.72 \\
\hline
\end{tabular}

Table.3 Relative mobility of the proteins for L. edodes strains

\begin{tabular}{|c|c|l|}
\hline Strains & No. of bands & Relative Mobility $(\mathrm{Rm})$ \\
\hline LeC & 6 & $0.11,0.43,0.53,0.66,0.72,0.81$ \\
\hline LeI & 5 & $0.10,0.42,0.64,0.71,0.80$ \\
\hline LeS & 7 & $0.04,0.22,0.32,0.39,0.46,0.67,0.78$ \\
\hline OE-38 & 6 & $0.02,0.20,0.36,0.44,0.66,0.78$ \\
\hline OE-142 & 5 & $0.02,0.36,0.45,0.66,0.78$ \\
\hline OE-329 & 8 & $0.04,0.10,0.27,0.37,0.46,0.61,0.68,0.78$ \\
\hline OE-388 & 7 & $0.02,0.22,0.30,0.36,0.45,0.68,0.78$ \\
\hline
\end{tabular}


Table.4 Rm values for different isozymes for $L$. edodes strains

\begin{tabular}{|c|c|c|c|c|c|c|}
\hline & \multicolumn{2}{|c|}{ Alcohol dehydrogenases } & \multicolumn{2}{c|}{ Malate dehydrogenases } & \multicolumn{2}{c|}{ Peroxidases } \\
\hline Strains & No. of bands & Rm values & No. of bands & Rm values & No. of bands & Rm values \\
\hline LeC & 0 & - & 0 & - & 1 & 0.66 \\
\hline LeI & 0 & - & 0 & - & 1 & 0.66 \\
\hline LeS & 1 & 0.13 & 2 & $0.35,0.54$ & 1 & 0.69 \\
\hline OE-38 & 1 & 0.13 & 0 & - & 1 & 0.62 \\
\hline OE-142 & 2 & $0.13,0.24$ & 1 & 0.35 & 1 & 0.62 \\
\hline OE-329 & 1 & 0.13 & 2 & $0.35,0.54$ & 1 & 0.62 \\
\hline OE-388 & 1 & 0.24 & 0 & - & 1 & 0.62 \\
\hline
\end{tabular}

Fig.1 Dendrogram showing relationship between different S. cerevisiae strains generated after PCR-RFLP analysis of ITS region using Treeconw software program

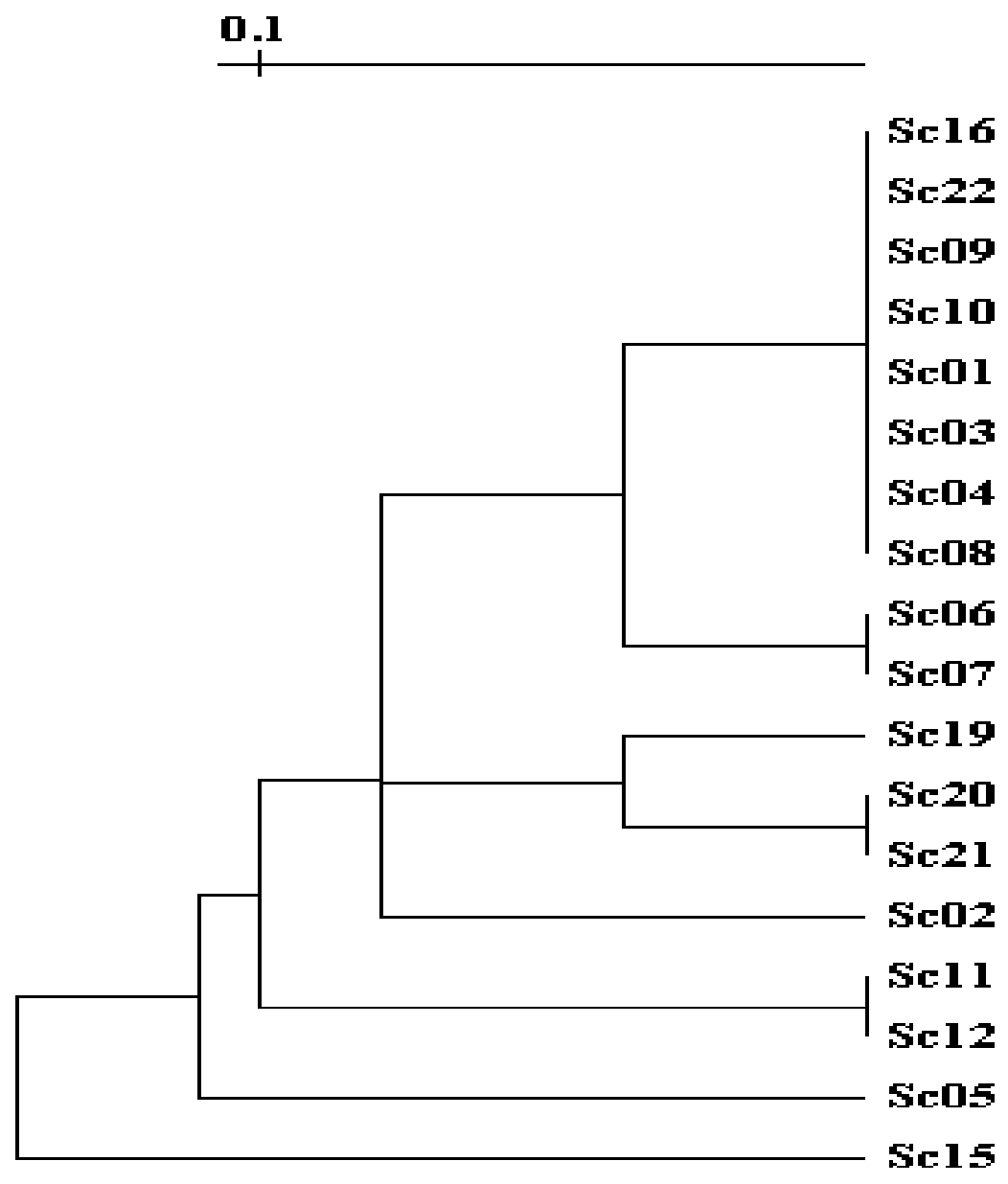


Plate.1 Protein profiling of 7 strains of L. edodes using SDS-PAGE

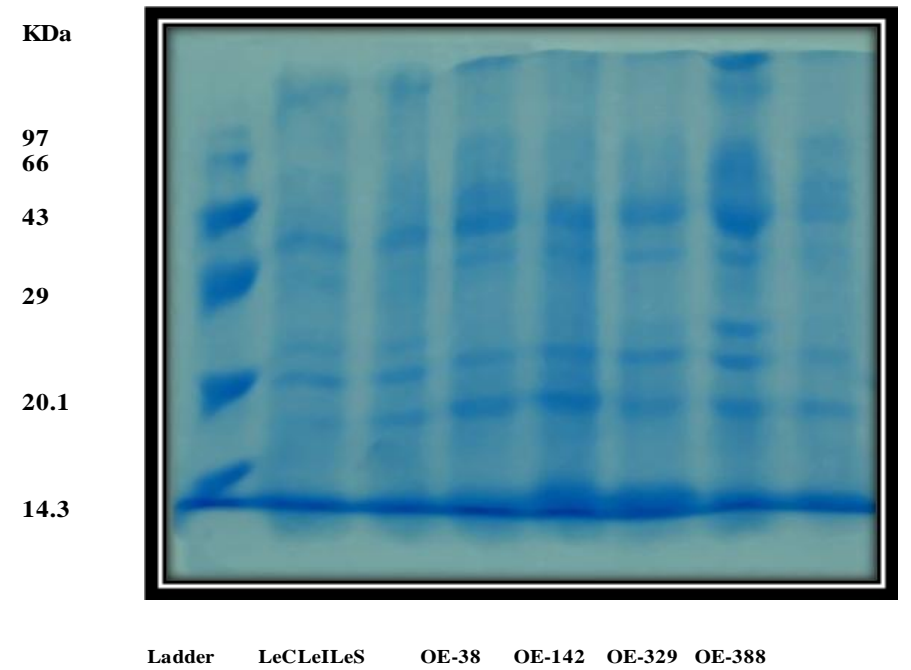

Fig.2 Restriction pattern shown by different S. cerevisiae strains after digestion with Alu I, Hae III, Hinf I and Taq I endonucleases

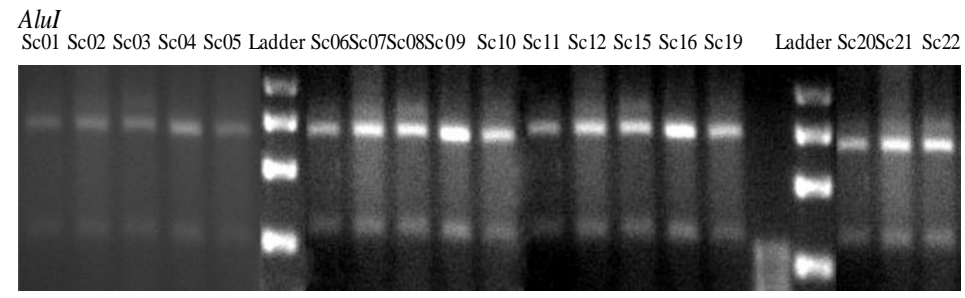

HaeIII

LadderSc01 Sc16 Sc03 Sc10Sc11Sc06Ladder Sc07Sc08Sc09Ladder Sc04Sc05Sc12Sc15Sc02Sc19Sc20 Sc21 Sc22

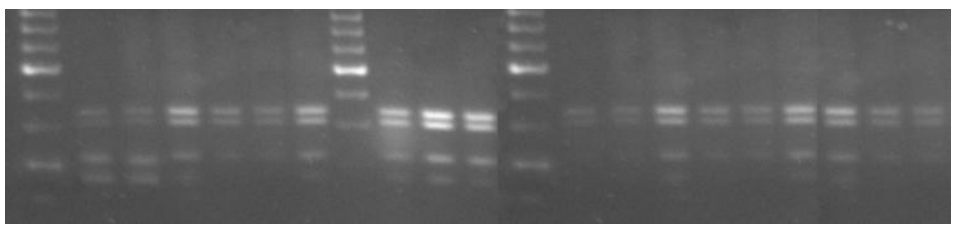

Hinf I

Ladder Sc01 Sc02 Sc03 Sc15 Sc05 Sc06 Sc07 Sc11 Sc12 Sc20 Sc08 Sc09 Sc04 Sc16Sc19Sc22Sc10Sc21Ladder

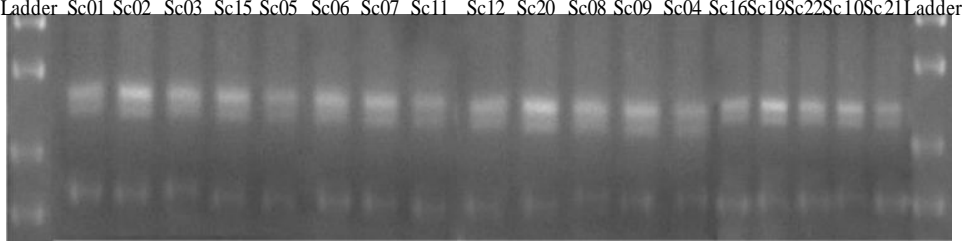

TaqI

Ladder Sc01 Sc02 Sc03Sc05 Sc04 Sc06 Sc07Sc08Sc09 Ladder Sc10Sc11 Sc20Sc15Sc16Sc19Sc12 Sc21Sc22

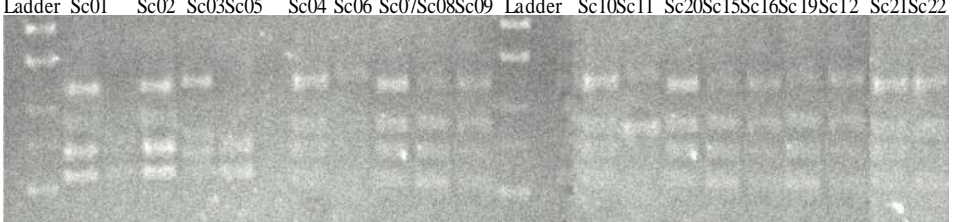


Plate.2 Native-PAGE of a. Alcohol Dehydrogenase b. Malate Dehydrogenase c. Peroxidase

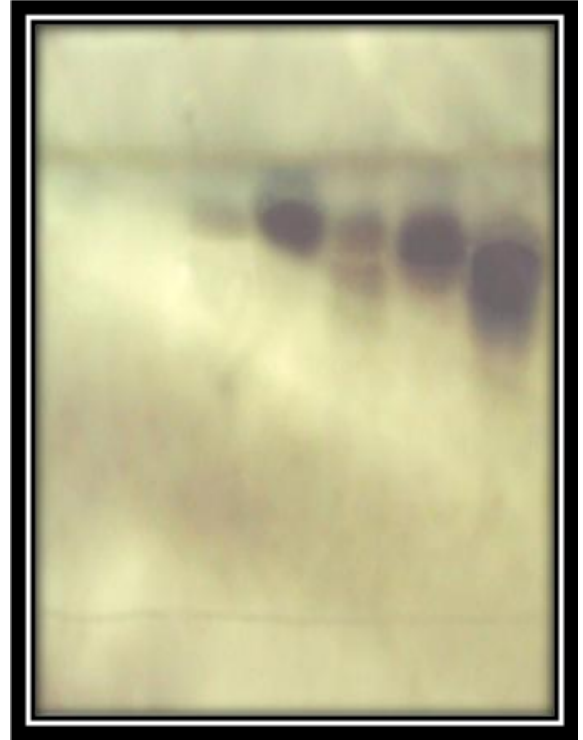

(a)

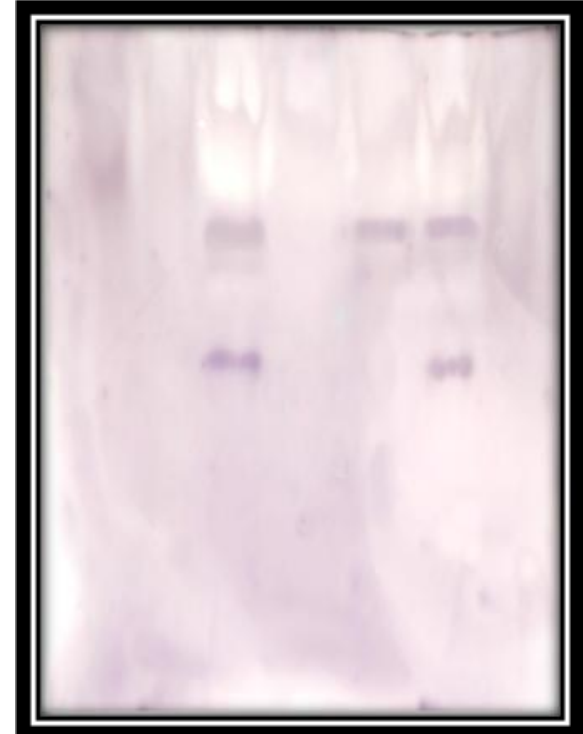

(b)

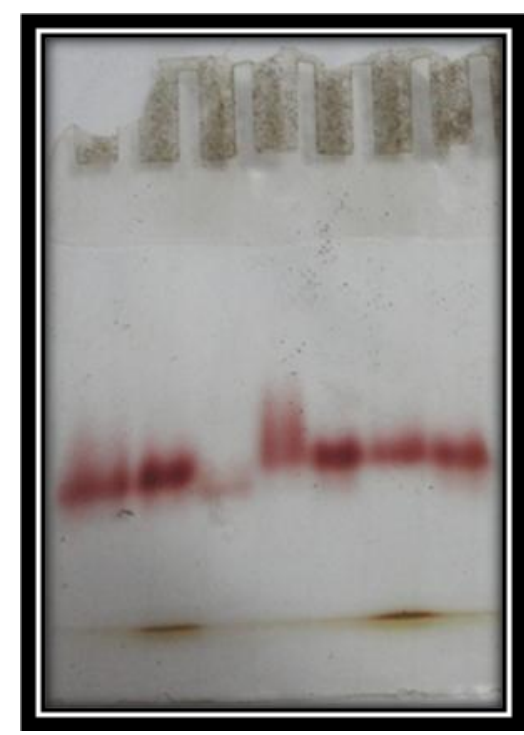

(c)

\section{Malate dehydrogenase}

Bands were obtained at $\mathrm{Rm}$ values corresponding to two isozymes (Plate $2 \mathrm{~b}$ ). Two bands were obtained in two strains of Lentinus (LeS and OE-329) at Rm values of 0.35 and 0.54 , a single band was found at $\mathrm{Rm}$ value of 0.35 in case of $\mathrm{OE}-142$ while no bands were found in LeC, LeI, OE-38 and OE-388 (Table 4). Ohamasa and Furukawa (1986) classified forty different strains of Lentinus edodes into five groups according to the typical bands of malate dehydrogenase $(\mathrm{MDH})$ and esterase. To analyze the genetic variability in the natural population of the fungus, electrophoretic patterns of nine enzymes from the mycelia of 93 strains of $L$. edodes from different countries were studied by Fukuda and Tokimoto (1991). They observed that the strains showed a high variation in esterase and malate dehydrogenase systems and suggested that geographical distance reduces the genetic similarity in the natural population of $L$. edodes. Tokimoto et al., (1998) observed six types of malate dehydrogenase enzymes in $L$. edodes.

\section{Peroxidase}

Three isozymes corresponding to $\mathrm{Rm}$ values of $0.62,0.66$ and 0.69 could be observed (Plate 2c). One band at $\mathrm{Rm}$ value of 0.66 was observed in LeC and LeI while in LeS, the band corresponding to $\mathrm{Rm}$ value of 0.69 was present (Table 4). However, one band at $\mathrm{Rm}$ value of 0.62 was present in OE-38, OE-142, OE-329 and OE-388. Baocheng et al., (1995) studied esterase and peroxidase isozyme pattern and showed that fusant strains of $P$. sapidus and $P$. ostreatus had bands from both the parents. Park et al., (1997) assessed the genetic similarity of sixty three isolates of $L$. edodes by isozyme polymorphisms and by combining the isozyme patterns of esterase, peroxidase and acid phosphatase, each isolate showed its own distinct electrophoretic phenotypes. The results of RAPD-PCR and ITS sequencing also revealed the divergent nature of LeC and LeI strains (Sharma et al., 2014).

In conclusion, the results of the present study revealed divergent nature of Saccharomyces cerevisiae as well as Lentinus edodes on the 
basis of their geographical origins. Four $S$. cerevisiae strains clustered separately from other strains corresponding to different locations during PCR-RFLP analysis. Two indigenous strains of $L$. edodes from Tamil $\mathrm{Nadu}$ Agricultural University, Coimbatore (LeC and LeI) showed different characteristics as compared to other strains as seen by protein profiling using SDS-PAGE and isozymes. This study shows these techniques to be a powerful tool to discriminate these fungal species at intraspecies level for their diversity analysis.

Conflict of Interest: Authors declare no conflict of interest.

\section{Acknowledgement}

Dr. Keshani acknowledge the Department of Science and Technology, Government of India, New Delhi for the INSPIRE fellowship sanction under order no. DST/INSPIRE Fellowship/2010/321 date 30 March 2011.

\section{References}

Baocheng, Z., Junyang, W., Keqin, Y., and Qingyu, L., 1995. Studies on isozyme of Pleurotus sapidus, Pleurotus ostreatus and their fusant strains. Hereditias 17, 37-39.

Bisen, P.S., Baghel, R.K., Sanodiya, B.S, Thakur, G. S., and Prasad, G. B., 2010. Lentinus edodes: A macrofungus with pharmacological activities. Curr. Med. Chem. 17(22), 2419-30.

Brown, A. H. D., Novo, E., Zohary, D., and Dagan, O., 1978. Genetic variation in natural populations of wild barley (Hordeum spontaneum). Genetica 49, 97-108.

Casey, G.P., Pringle, A.T., and Erdmann, P.A., 1990. Evaluation of recent techniques used to identify individual stains of Saccharomyces yeasts. J. Am. Soc. Brew. Chem. 48, 100-106.

Chakraborty, U., and Sidkar, R. S., 2010. Intergeneric protoplast fusion between Calocybe indica (milky mushroom) and Pleurotus florida aids in the qualitative and quantitative improvement of sporophore of the milky mushroom. World J. Microb. Biot. 26, 213-225.

Chakraborty, U., and Sikdar, S. R., 2008. Production and characterization of somatic hybrids raised through protoplast fusion between edible mushroom strains Volvariella volvacea and Pleurotus florida. World J. Microb. Biot. 24, 1481-1492.

Feibelman, T., Bayman, P., and Cibula, W., 1994. Length variation in the internal transcribed spacer of ribosomal DNA in chanterelles. Mycol. Res. 98, 614618.

Fukuda, M., and Tokimoto, K., 1991. Variation of isozyme patterns in the natural population of Lentinus edodes. Proc. Japan Acad. 67(B), 43-47.

Guikema, J. A., and Sherman, L. A., 1980. Electrophoretic profiles of cyanobacterial membrane polypeptides showing hemedependent peroxidase activity. Biochim. Biophys. Acta 637, 189-201.

Hobbs, C., 2000. Medicinal value of Lentinus edodes (Berk.) Sing.: A literature review. Int. J. Med. Mushrooms 2, 287-302.

Kanwar, S.S., and Keshani, 2014. Bioprospecting of indigenous yeast isolates of fermented foods of NorthWestern Himalayas. Advances in Industrial Biotechnology. Ram Sarup Singh, Ashok Pandey \& Christian Larroche (Eds.) IK International Publishing House Pvt. Ltd., India, pp 180-195 (ISBN 978-93-82332-76-3)

Kanwar, S.S., Keshani, 2016. Fermentation of 
apple juice with a selected yeast strain isolated from fermented foods of Himalayan regions and its organoleptic properties. Front. Microbiol. $\quad 7, \quad 1012$. http://dx.doi.org/10.3389/fmicb.2016. 01012.

Keshani, Sharma, P.N., Sharma, K.D., and Kanwar, S.S. 2015. Molecular and functional diversity of Saccharomyces cerevisiae strains of traditional fermented foods of the North-Western Himalayas. Ann. Microbiol. 65, 22652275.

Kobayashi, H., Itagaki, T., Inokuchi, N., Ohgi, K., Nada, T., Iwama, M., and Irie, M., 2003. A new type of RNase $\mathrm{T}_{2}$ ribonuclease in two basidiomycetes fungi, Lentinus edodes and Irpex lacteus. Biosci. Biotechnol. Biochem. 67(10), 2307-2310.

Laemmli, U. K., 1970. Cleavage of structural proteins during the assembly of the head of bacteriophage T4. Nature 227(5259), 680-685.

Le, Q.V., Won, H.K., Lee, T.S., Lee, C.Y., Lee, H.S., and Ro, H.S. 2008. Retrotransposon microsatellite amplified polymorphism strain fingerprinting markers applicable to various mushroom species. Mycobiology 36(3), 161-166.

Lowry, O.H., Rosebrough, N.J., Farr, A.L., and Randall, R.J. 1951. Protein measurements with Folin Phenol Reagent. J. Biol. Chem. 193, 265-275.

Magee, B.B., D'Souza, T.M., and Magee, P.T. 1987. Strain and species identification by restriction fragment length polymorphisms in the ribosomal DNA repeat of Candida species. J. Bacteriol. 169, 1639-1643.

Martorell, P., Querol, A., and FernandezEspinar, M.T. 2005. Rapid identification and enumeration of Saccharomyces cerevisiae cells in wine by real-time PCR. Appl. Environ. Microbiol. 71, 6823-6830.

Mehmood, S., Bashir, A., Ahmad, A., Akram, Z., Jabeen, N., and Gulfraz, M. 2008. Molecular characterization of regional Sorghum bicolor varieties from Pakistan. Pakistan J. Bot. 40, 20152021.

Molina, F.I., Jong, S.C., and Huffman, J.L. 1993. PCR amplification of the $3^{\prime}$ external transcribed and intergenic spacer of the ribosomal DNA repeat unit in three species of Saccharomyces. FEMS Microbiol. Lett. 108, 259-264.

Ohamasa, M., and Furukawa, H., 1986. Analysis of esterase and malate dehydrogenase isozymes of Lentinus edodes by isoelectric focussing for identification and discrimination of stocks. Trans. Mycol. Soc. Jpn. 27, 79-90.

Park, W. M., Ko, H. G., Park, R. J., Hong, K. S., and Kim, G. H., 1997. Differentiation of Lentinus edodes isolates in Korea by isozyme polymorphisms and Random Amplified Polymorphic DNA (RAPD) analysis. Korean J. Mycol. 25(3), 176190.

Pedersen, M. B. 1986. DNA sequence polymorphisms in the genus Saccharomyces. IV. Homologous chromosomes III of Saccharomyces bayanus, $S$. carlsbergensis and $S$. uvarum. Carlsberg Res. Commun. 51, 185-202.

Sharma, S., Khanna, P.K., and Kapoor, S. 2014. Molecular characterization of shiitake medicinal mushroom, Lentinus edodes strains (higher basidiomycetes) using RAPD and ITS sequencing. Int. J. Med. Mushrooms 16(2), 185-193.

Tanksley, S. D. 1979. Linkage, chromosomal association and expression of Adh-1 
and Pgm-2 in tomato. Biochem. Genet., 17, 1159-1167.

Thetsrimuang, C., Khammuang, S., and Samthima, R. 2011. Antioxidant activity of crude polysaccharides from fresh and dry mushroom fruiting bodies of Lentinus sp. strain RJ-2. Int. J. Pharmacol. 7(1), 58-65.

Tokimoto, K., Fukuda, M., and Tsuboi, M. 1998. Effect of the physical properties of Lentinula edodes bedlogs on fruiting body production. Mycoscience 39, 217-219.

Vetchinkina, E. P., Sokolov, O. I., and Nikitina, V. E. 2008. Intracellular lectins of Lentinus edodes at various developmental stages of the fungus. Microbiology 77(4), 441-445.

Walia, S., Keshani, Sood, S., and Kanwar, S.S. 2014. Exhibition of DNAbioprotective activity by microflora of traditional fermented foods of NorthWestern Himalayas. Food Res. Int. 55, 176-180.

Walther, A., Hesselbart, A., and Wendland, J. 2014. Genome sequence of Saccharomyces carlsbergensis, the world's first pure culture lager yeast. G3: Genes, Genomes, Genetics. Doi: 10.1534/g3.113.010090.

\section{How to cite this article:}

Keshani, Shivani Sharma, S.S. Kanwar, P.K. Khanna and Shammi Kapoor. 2018. Region based Diversity Studies of Saccharomyces cerevisiae and Lentinula edodes. Int.J.Curr.Microbiol.App.Sci. 7(07): 3702-3713. doi: https://doi.org/10.20546/ijcmas.2018.707.428 